\begin{tabular}{|l|l|l||}
\hline \multicolumn{2}{|c|}{ PublisherInfo } \\
\hline \hline PublisherName & $:$ & BioMed Central \\
\hline \hline PublisherLocation & $:$ & London \\
\hline \hline PublisherImprintName & $:$ & BioMed Central \\
\hline \hline
\end{tabular}

\title{
Putting the heat into heat-shock
}

\begin{tabular}{|l|l|l||}
\hline \multicolumn{2}{|c|}{ ArticleInfo } \\
\hline \hline ArticleID & $:$ & 4326 \\
\hline \hline ArticleDOI & $:$ & $10.1186 /$ gb-2002-3-3-reports0016 \\
\hline \hline ArticleCitationID & $:$ & reports0016 \\
\hline \hline ArticleSequenceNumber & $:$ & 21 \\
\hline \hline ArticleCategory & $:$ & Paper report \\
\hline \hline ArticleFirstPage & $:$ & 1 \\
\hline \hline ArticleLastPage & $:$ & 4 \\
\hline \hline & & RegistrationDate : 2002-1-10 \\
ArticleHistory & $:$ & Received \\
& & OnlineDate $2002-1-10$ \\
\hline \hline ArticleCopyright & $:$ & BioMed Central Ltd2002-2-28 \\
\hline \hline ArticleGrants & $:$ & \\
\hline \hline
\end{tabular}




\begin{tabular}{|l|l|l||}
\hline ArticleContext & $: 130593333$ \\
\hline
\end{tabular}

\section{Chris Berrie}

\section{Abstract}

The expression of several heat-shock proteins of nitrogen-fixing bacteria is controlled posttranscriptionally by the thermosensitive secondary structure of the 'ROSE' regulatory sequences in their mRNA

\section{Significance and context}

Exposure of cells to a sudden rise in temperature leads to the protective 'heat-shock response' that induces the synthesis of a group of highly-specialized heat-shock proteins (HSPs). Many HSPs are molecular chaperones (for example, the bacterial DnaK, GroEL) or ATP-dependent proteases (for example Lon and Clp) involved in the modulation of protein folding, assembly, repair and degradation. In response to heat shock, bacteria have at least two main transcriptional control strategies. One is the transient up-regulation of heat-shock-gene expression via the transcription factor $\sigma^{32}(\mathrm{RpoH})$. The other is the induction of transcription of heat-shock genes by removal of repressor proteins bound to specific DNA regions, such as the CIRCE repeat (controlling inverted repeat of chaperone expression). In various rhizobial species, a further regulatory element that controls at least five heat-shock operons consists of a conserved 100 base-pair DNA segment in the 5'-untranslated region, between the transcriptional and translational start sites, called the ROSE element (repression of heat-shock gene expression). Having searched unsuccessfully for transcriptional control via a cognate ROSE-binding repressor protein, Nocker et al. looked for a new, post-transcriptional, control mechanism at mRNA level.

\section{Key results}

The authors show that the secondary structure of the highly conserved 3' end of the ROSE element in the mRNAconstitutes a functionally important direct thermosensor. As this stem-loop structure contains the Shine-Dalgarno ribosome-binding site and the translational start codon, it renders them both unavailable for interaction with their normal partners to allow translation. At heat-shock temperatures, base pairing breaks down and the structure 'melts', making the site available for ribosome binding. This protects the transcript from further degradation and initiates its translation. 


\section{Methodological innovations}

Nocker et al. used the latest mfold program for the prediction of RNA secondary structures. They describe the highly conserved 3' ends of ROSE from different rhizobial mRNAs that form very similar secondary structures. Random single-nucleotide mutations of ROSE 1 were selected, after their generation by error-prone PCR, with further site-directed mutagenesis of potentially important residues. The mutated translational $R_{O S E_{1}}$-hspA-lacZ fusions were integrated into the chromosomes of both Bradyrhizobium japonicum and Escherichia coli, using $\alpha$-galactosidase activity to monitor the effects of the mutations on the derepression of ROSE 1 at $30^{\circ} \mathrm{C}$ in both microorganisms, and at $37^{\circ} \mathrm{C}$ in the latter.

\section{Conclusions}

The authors give examples of the secondary structures of the highly conserved 3' ends of ROSE mRNAs from four different rhizobial species. The functionality of the ROSE 1 element arises from the maintenance of secondary structure base pairing both in this 3' portion and in a more central stem-loop structure. Removal of the unpaired, bulged G83 residue (which is invariant across all known ROSE elements), or introduction of extra base pairing throughout the internal loops of the $3^{\prime}$ portion of ROSE 1 , results in a loss of derepression even at $37^{\circ} \mathrm{C}$ in E. coli. Finally, mutations removing base-pairing around the G83 residue, exposing the Shine-Dalgarno sequence, cause derepression at $30^{\circ} \mathrm{C}$ which is coupled to an increase in transcript levels. These secondary-structure predictions and alterations show the functional importance of the temperature-sensitivity of translation of mRNAs containing ROSE elements.

\section{Reporter's comments}

The concept of reversible, temperature-controlled conformational changes being used to control gene expression is not entirely new. At the transcriptional level, it occurs in the action of the RheA repressor in Streptomyces albus. At the post-transcriptional level, the secondary structure of the $r p o H$ mRNA of $E$. coli also undergoes thermal melting at the initiation region that facilitates translation of the transcription factor $\sigma^{32}$. Nocker et al. have shown a more direct, ROSE 1 -mediated, thermosensor control of the HSPs themselves. Furthermore, at $30^{\circ} \mathrm{C}$ there are low levels of transcript present even though the promoter is constitutive in nature, and the release of base-pairing around G83 leads to an elevation of these transcript levels. The 3 ' end of ROSE thus provides this direct thermosensing role that is coupled to protection from mRNA degradation by ribosomal association, with the overall mRNA secondary structure aiding the fine-tuning of the response.

As the authors also indicate, the mechanisms behind this direct thermosensor role for ROSE will allow further investigation not only into ROSE-mediated regulation of transcription, but also into other 
potential examples of thermoregulation. Given the lengthening list of diseases in which processing and stability of mRNA is impaired, such as spinal muscular atrophy, growth hormone deficiency, hyperferritinemia, hereditary thrombocythemia and thrombophilia, and $\beta$-thalassemia, the understanding of this mechanism of control will help in the elucidation of disease pathogenesis and the promotion of rational therapeutic strategies.

\section{Table of links}

Nucleic Acids Research

mfold program

\section{References}

1. Nocker A, Hausherr T, Balsiger S, Krstulovic N-P, Hennecke H, Narberhaus F: A mRNA-based thermosensor controls expression of rhizobial heat shock genes. Nucleic Acids Res. 2001, 29:

4800-4807. 0305-1048 